(2019) 25 JUUM 15 - 22

https://doi.org./10.17576/juum-2019-25-03

\title{
Mampukah Perintah Berkurung Membanteras Jenayah dalam Kalangan Remaja di Malaysia?
}

\author{
(Can Curfew Combat Crime Among Teenagers in Malaysia?) \\ MUHAMAD SAYUTI HASSAN @, YAHYA \\ ROZANA ABDULLAH
}

ABSTRAK

\begin{abstract}
Kejadian jenayah dalam kalangan masyarakat sangat membimbangkan. Menurut statistik jenayah oleh Kementerian Dalam Negeri, jumlah jenayah yang direkodkan berdasarkan kertas siasatan yang dibuka ialah 657,174 sepanjang tahun 2012 hingga tahun 2016. Pada 17 Januari 2019, kerajaan berhasrat untuk mengkaji pelaksanaan perintah berkurung kepada remaja bawah umur 18 tahun bagi membendung kegiatan jenayah dalam kalangan remaja pada waktu malam. Sehubungan dengan itu, objektif utama artikel ini adalah untuk menganalisis isu perintah berkurung terhadap remaja yang berusia kurang daripada 18 tahun menurut perspektif undang-undang. Pada masa yang sama, artikel ini juga akan menerangkan kedudukan perlakuan jenayah yang melibatkan remaja dengan memfokuskan kepada jenayah penyalahgunaan dadah. Di samping itu, artikel ini turut meninjau amalan beberapa buah negara luar berhubung dengan undang-undang yang berkaitan dengan perintah berkurung kepada remaja. Artikel ini mendapati bahawa terdapat kelompangan undang-undang berhubung dengan perintah berkurung kepada remaja bawah 18 tahun di Malaysia. Oleh hal yang demikian, pelbagai pertimbangan dan kajian lebih terperinci perlu dibuat sekiranya kerajaan serius untuk melaksanakan perintah berkurung kepada remaja bawah 18 tahun. Cadangan pewujudan undang-undang berhubung dengan perintah berkurung ini haruslah bersifat holistik tanpa melanggar peruntukan perlembagaan persekutuan dan prinsip hak asasi manusia. Oleh itu, hasrat murni kerajaan untuk membanteras jenayah dalam kalangan remaja wajar disokong dan pada masa yang sama aspek cadangan pelaksanaan perintah berkurung terhadap remaja bawah 18 tahun juga perlu diteliti sedalam-dalamnya.
\end{abstract}

Kata kunci: Remaja bawah umur, jenayah, perintah berkurung, remaja, undang-undang

\section{ABSTRACT}

The incidence of crime in the community is alarming. According to the crime statistics by the Ministry of Home Affairs, the number of crimes recorded based on investigation papers was 657,174 throughout 2012 to 2016. On January 17, 2019, the Government intends to review the implementation of curfew orders for minors under the age of 18 to curb criminal activity among teenagers at night. In this regard, the main objective of this article is to analyze the issue of curfew for juveniles under 18 from a legal perspective. This article explains the position of criminal behavior involving adolescents by focusing on drug abuse. In addition, this article also reviews the practices of several countries in relations to juvenile curfew law. This article found that there is lacuna in the Malaysian law in relation to curfew orders for minors under 18. As such, there are various considerations and a more detailed study needs to be done if the Government is serious about executing curfew orders for teens under 18. Proposed legislation in relations to the curfew should be holistic in nature without violating the provisions of the Federal Constitution and human rights principles. Therefore, the Government's effort to curb crime among teenagers should be supported and at the same time the proposal to implement curfew for jurveniles under the age of 18 should also be carefully considered.

Keywords: Under age; crime; curfew; teenagers; legal

\section{PENGENALAN}

Menurut Indeks Keamanan Global 2017 (Global Peace Index), Malaysia berada di kedudukan ke-29 di belakang Bulgaria dengan mencatatkan skor sebanyak 1.637 dengan bacaan tinggi (zon berwarna hijau). Jika dilihat secara perbandingan dengan negara di Asia Tenggara, Malaysia berada di kedudukan yang kedua selepas Singapura yang berada di kedudukan ke-21 dengan mencatatkan skor sebanyak 1.534 yang juga diklasifikasikan sebagai bacaan tinggi (hijau). Di peringkat Asia Pasifik pula, Indeks Keamaan Global 2017 telah mencatatkan Malaysia berada di kedudukan kelima di belakang Singapura, Australia, Jepun dan kedudukan teratas ialah New Zealand dengan 
bacaan skor 1.241. Walaupun kedudukan GPI Malaysia berkedudukan baik berbanding dengan beberapa negara ASEAN yang lain, hakikatnya masyarakat masih dibelenggu dengan pelbagai kes jenayah. Sehubungan dengan itu, satu inisiatif yang dilancarkan oleh kerajaan adalah melalui Bidang Keberhasilan Utama Nasional (NKRA), iaitu mengurangkan jenayah. Terdapat tiga aspek yang diberikan keutamaan iaitu jenayah jalanan, keselamatan awam dan juga peningkatan agensi penguatkuasaan.

Oleh itu, artikel ini menetapkan tiga objektif, iaitu pertama, untuk menerangkan statistik dan keadaan jenayah dalam kalangan remaja di Malaysia. Objektif kedua adalah untuk menganalisis amalan perintah berkurung kepada remaja dari perspektif undang-undang, manakala objektif ketiga pula adalah untuk meninjau pelaksanaan amalan perintah berkurung di beberapa negara luar. Bagi mencapai keseluruhan objektif dalam penulisan ini, artikel ini menggunakan pendekatan sosioperundangan.

\section{STATISTIK DAN KEADAAN JENAYAH DI MALAYSIA}

Kejadian kes jenayah di Malaysia merekodkan jumlah yang agak tinggi. Jumlah yang direkodkan berdasarkan kertas siasatan yang dibuka ialah 657,174 kes bagi tempoh sepanjang tahun 2012 hingga tahun 2016. Merujuk kepada Rajah 1 di bawah, rekod jumlah jenayah didapati menurun dari tahun 2012 hingga tahun 2016. Sepanjang tempoh lima (5) tahun ini, tahun 2012 mencatatkan jumlah rekod jenayah paling tinggi iaitu sebanyak 153,669 kes. Rekod bacaan terendah bagi tempoh lima (5) tahun pula adalah pada tahun 2016 iaitu sebanyak 112,354 kes. Jumlah kes jenayah tersebut mewakili kedua-dua kumpulan, iaitu jenayah kekerasan dan jenayah harta benda.

Kupasan statistik ini merujuk beberapa statistik yang dikeluarkan oleh Kementerian Dalam Negeri yang diperoleh melalui laman web seperti yang dinyatakan dalam sumber selepas ini. Berdasarkan Rajah 1 di bawah, jumlah keseluruhan berhubung dengan dua jenis jenayah kekerasan dan harta benda ialah 112,354 kes di seluruh Malaysia pada tahun 2016. Jumlah tersebut menurun berbanding dengan sebanyak 115,545 kes pada tahun 2015. Statistik yang dibincangkan berdasarkan nombor kes siasatan.

Untuk kupasan lanjut, artikel ini memfokuskan kepada jenayah penyalahgunaan dadah. Hal ini kerana jenayah ini banyak berlaku dalam masyarakat dan remaja berumur bawah 18 tahun, iaitu dalam kalangan kelompok yang mudah terjebak kepada jenayah ini. Tumpuan terhadap jenayah dalam kalangan remaja berumur bawah 18 tahun ini adalah penting agar dapat mengelakkan kejadian kebakaran seperti yang berlaku di Pusat Tahfiz Darul Quran Ittifaqiyah yang mengorbankan 23 nyawa, termasuk 21 pelajar pada 24 September 2017 berlaku lagi. Kejadian ini dilakukan berdasarkan perancangan rapi sekumpulan tujuh remaja berusia di antara 11 dengan 18 tahun yang bermotifkan balas dendam. Menurut pakar kriminologi Universiti Sains Malaysia, Prof Madya Dr. P. Sundramoorthy, trend penglibatan remaja berusia

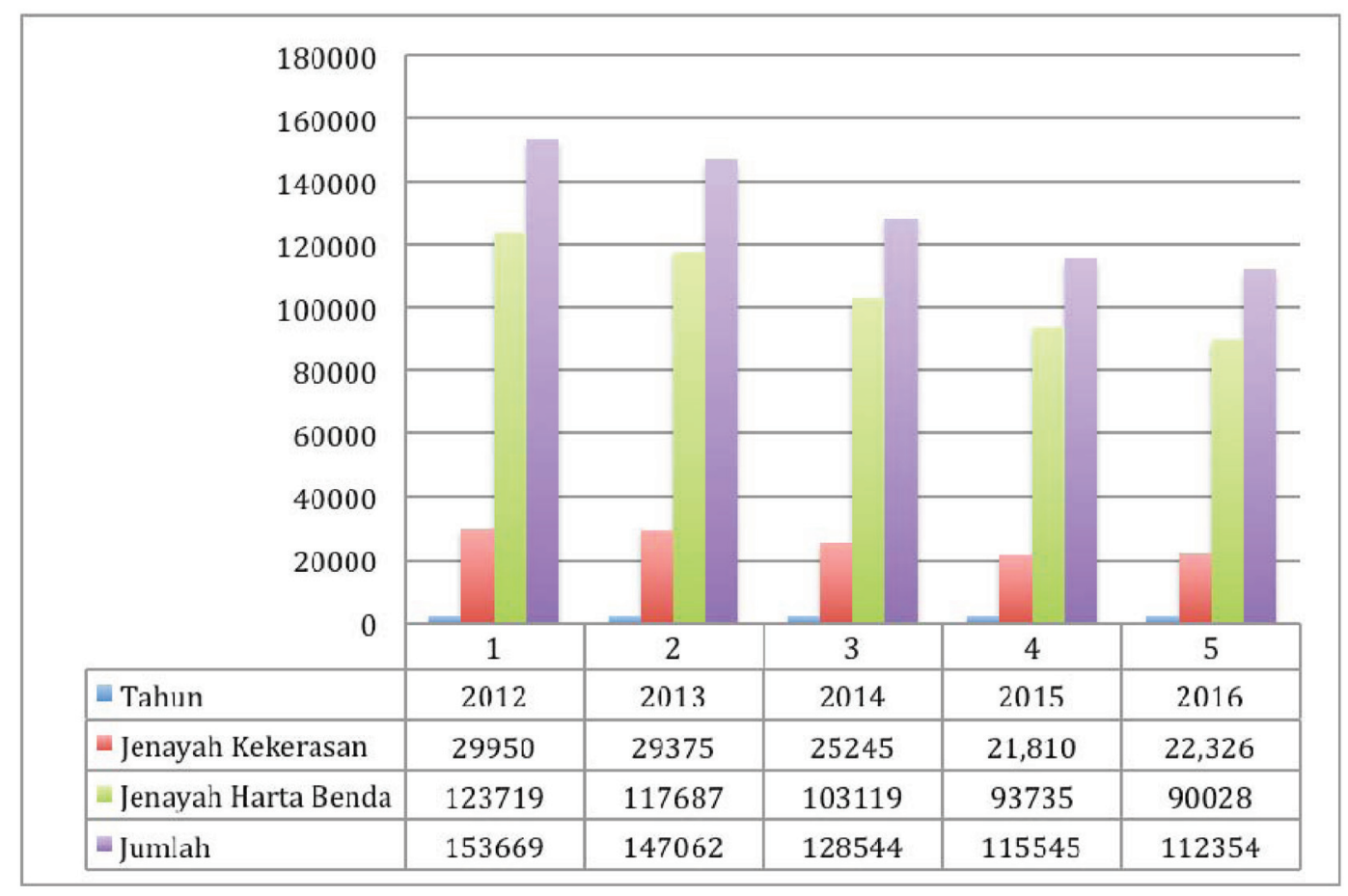

RAJAH 1 Jumlah jenayah di seluruh dari tahun Malaysia 2012 hingga tahun 2016

Sumber: MAMPU (www.data.gov.my) 
bawah 14 tahun dengan menggunakan keganasan untuk menyelesaikan masalah tanpa memikirkan kesannya dilihat semakin berkembang di negara ini, namun tiada data yang cukup mengenai betapa serius perkara tersebut. ${ }^{1}$

Dalam konteks ini, menurut statistik dalam Jadual 1 yang disediakan oleh Kementerian Dalam Negeri, statistik jenayah penyalahgunaan dadah menunjukkan peningkatan dari tahun ke tahun iaitu jumlah sehingga 2016 ialah 30,844 kes. Berikut adalah statistik lanjut berhubung penyalahgunaan dadah di Malaysia:

JADUAL 1 Jumlah penagih yang dikesan mengikut status kes dari tahun 2010 hingga tahun 2016

\begin{tabular}{lccc}
\hline Tahun & Kes Baru & Berulang & Jumlah \\
\hline 2010 & 17,238 & 6,404 & 23,642 \\
2011 & 13,683 & 5,848 & 19,531 \\
2012 & 10,301 & 4,800 & 15,101 \\
2013 & 13,481 & 7,406 & 20,887 \\
2014 & 13,605 & 8,172 & 21,777 \\
2015 & 20,289 & 6,379 & 26,668 \\
2016 & 22,923 & 7,921 & 30,844 \\
\multicolumn{5}{c}{ Jumlah Keseluruhan } \\
\hline
\end{tabular}

Statistik jenayah dadah di Malaysia adalah berpunca daripada pelbagai faktor antaranya ialah pengaruh kawan, untuk keseronokan, perasaan ingin tahu rangsangan, menahan sakit, secara tidak sengaja, tekanan jiwa dan lain-lain. Seperti yang diterangkan dalam Jadual 2, statistik berkenaan yang menunjukkan bahawa pengaruh rakan merupakan faktor utama penularan kes jenayah penyalahgunaan dadah iaitu sebanyak 17,990 kes pada tahun 2016. Faktor kedua tertinggi ialah perasaan ingin tahu iaitu sebanyak 5618 kes pada tahun 2106 diikuti dengan faktor untuk keseronokan iaitu sebayak 3,944 kes pada tahun yang sama.

Tambahan pula, Jadual 3 di bawah menunjukkan statistik penyalahgunaan dadah dalam kalangan remaja bawah 19 tahun. Terdapat trend yang meningkat bermula tahun 2012 sehingga tahun 2016 dan catatan jumlah 1,595 kes bagi remaja berumur antara 16 hingga 19 tahun ini adalah sesuatu yang sangat membimbangkan.

JADUAL 3 Jumlah penagih dadah mengikut umur

\begin{tabular}{lccr}
\hline Tahun & $<13$ & $13-15$ & $16-19$ \\
\hline 2010 & 3 & 83 & 2,610 \\
2011 & 15 & 55 & 1,425 \\
2012 & 0 & 28 & 855 \\
2013 & 0 & 18 & 847 \\
2014 & 0 & 28 & 1,173 \\
2015 & 0 & 45 & 1375 \\
2016 & 0 & 85 & 1,595 \\
\hline
\end{tabular}

Sumber: Kementerian Dalam Negeri

Dapatan ini menunjukkan bahawa jenayah yang berlaku membimbangkan masyarakat. Hal ini bermaksud tindakan membanteras jenayah perlu diperkasakan dan diperkemas lagi. Pandangan ini tidak menafikan keberkesanan program pembasmian jenayah yang sedia ada. Namun, aspek pendidikan dan literasi undangundang jenayah dalam masyarakat perlu diperluas agar usaha membanteras jenayah di negara ini dapat dilaksanakan dengan lebih berkesan. Oleh hal yang demikian, bahagian berikutnya menghuraikan cadangan amalan perintah berkurung yang boleh dipertimbangkan oleh kerajaan dalam membasmi jenayah penyalahgunaan dadah dalam kalangan remaja di Malaysia.

\section{PERINTAH BERKURUNG MENURUT PERSPEKTIF UNDANG-UNDANG}

Dengan melihat kepada statistik yang dipamerkan oleh Jadual 1 dan 2, terdapat keperluan bagi negara ini untuk meninjau kembali perlaksanaan perintah berkurung bagi remaja di bawah umur 18 tahun. Langkah untuk membanteras gejala negatif dalam kalangan kanak-kanak melalui pelaksanaan perintah berkurung ini adalah seiring dengan peruntukan yang ditetapkan oleh Konvensyen

JADUAL 2 Statistik sebab guna dadah, 2010-2016

\begin{tabular}{|c|c|c|c|c|c|c|c|c|c|c|}
\hline & A & B & $\mathrm{C}$ & $\mathrm{D}$ & $\mathrm{E}$ & $\mathrm{F}$ & G & $\mathrm{H}$ & & \\
\hline Tahun & $\begin{array}{c}\text { Untuk } \\
\text { Keseronokan }\end{array}$ & $\begin{array}{l}\text { Pengaruh } \\
\text { Kawan }\end{array}$ & $\begin{array}{c}\text { Perasaan } \\
\text { Ingin Tahu }\end{array}$ & Rangsangan & $\begin{array}{l}\text { Menahan } \\
\text { Kesakitan }\end{array}$ & $\begin{array}{c}\text { Secara } \\
\text { Tidak Sengaja }\end{array}$ & $\begin{array}{c}\text { Tekanan } \\
\text { Jiwa }\end{array}$ & $\begin{array}{l}\text { Lain- } \\
\text { lain* }\end{array}$ & Maklumat & Jumlah \\
\hline 2010 & 3,314 & 10,214 & 4,453 & 363 & 236 & 83 & 1,207 & 2,965 & 807 & 23,642 \\
\hline 2011 & 2,549 & 7,691 & 3,912 & 168 & 231 & 59 & 940 & 2,294 & 1,687 & 19,531 \\
\hline 2012 & 2,106 & 6,004 & 3,171 & 162 & 199 & 41 & 751 & 1,849 & 818 & 15,101 \\
\hline 2013 & 1,663 & 11,935 & 3,824 & 185 & 458 & 19 & 2,566 & 711 & 0 & 21,361 \\
\hline 2014 & 2,270 & 13,466 & 3,221 & 174 & 461 & 25 & 1,986 & 752 & 0 & 22,355 \\
\hline 2015 & 2,550 & 16,943 & 4,523 & 206 & 617 & 9 & 1,572 & 1059 & 0 & 27,479 \\
\hline 2016 & 3,944 & 17,990 & 5,618 & 145 & 698 & 17 & 1,910 & 1442 & 0 & 31,764 \\
\hline
\end{tabular}

Sumber: Kementerian Dalam Negeri 
tentang Hak Kanak-Kanak (KHK), melalui Bahagian 1(3) yang memperuntukkan bahawa:

Segala tindakan berkenaan dengan kanak-kanak hendaklah mengambil kira sepenuhnya kepentingan terbaik kanakkanak itu. Negara hendaklah memberi kanak-kanak itu jagaan yang mencukupi apabila ibu bapa atau orang lain yang dipertanggungjawabkan dengan tanggungjawab itu, gagal berbuat demikian.

Perkara 3 KHK menetapkan keperluan bagi negaranegara anggota yang meratifikasi Konvensyen ini, untuk memastikan bahawa kanak-kanak diberi perlindungan dan jagaan yang sewajarnya. Kerajaan Malaysia telah meratifikasi dan menandatangani KHK pada 17 Mac 1995. KHK telah mula berkuat kuasa pada 2 September 1990, dan sehingga 31 Disember 2008, sebanyak 193 buah negara telah meratifikasi KHK. ${ }^{2}$ Sebagai sebuah negara anggota, Malaysia mempunyai obligasi dalam memastikan sistem perundangan negara adalah seiring dengan piawaian yang ditetapkan oleh KHK. Sejajar dengan itu, sekiranya Malaysia berhasrat untuk menguatkuasakan perintah berkurung terhadap remaja bawah umur 18 tahun, pengecualian perlu diberikan kepada beberapa perkara, seperti yang disebutkan dalam Bahagian 1(32) KHK seperti yang berikut:

Kanak-kanak mempunyai hak kepada masa lapang, bermain dan menyertai aktiviti kebudayaan dan kesenian.

Perkara 32 ini menegaskan bahawa negara-negara anggota hendaklah menghormati dan menggalakkan hak kanak-kanak untuk menyertai sepenuhnya dalam kehidupan kebudayaan dan kesenian, dan hendaklah menggalakkan peluang penyertaan yang sesuai dan sama bagi aktiviti kebudayaan, kesenian, rekreasi dan masa lapang.

Selaras dengan Perkara 32 ini, undang-undang perintah berkurung di Amerika Syarikat telah menetapkan bahawa remaja hanya dibenarkan keluar malam untuk mematuhi suruhan ibu bapa atau penjaga mereka, berulang alik ke tempat kerja atau sekolah (jika ada aktiviti pada malam hari), atau menyertai apa-apa aktiviti awam atau keagamaan yang sah. ${ }^{3}$ Dalam kes Qutb vs Bartlett (1994), plaintif (seorang ibu dan anak perempuannya) mencabar kesahan undang-undang perintah berkurung di bandar Dallas yang dikuatkuasakan pada 1991. Setelah keputusan dibuat oleh Mahkamah Litar Kelima dan diterima oleh Mahkamah Amerika Syarikat, rayuan yang dibawa ke Mahkamah Agung Amerika Syarikat memutuskan bahawa undang-undang perintah berkurung defendan yang mengandungi banyak pengecualian adalah sah kerana matlamat utama adalah untuk mengurangkan jenayah remaja dan pemangsaan dengan mengenakan sekatan paling minimum. ${ }^{4}$

Dalam aspek ini, terdapat pelbagai kajian lalu yang membahaskan kewajaran perintah berkurung. Antaranya, Townsend menyokong pelaksanaan perintah berkurung dengan menjelaskan kepentingan mencegah jenayah dalam kalangan remaja berbanding dengan menghukum atas kesalahan mereka kelak. ${ }^{5}$ Walau bagaimanapun, Buck yang tidak bersetuju dengan Townsend percaya bahawa perintah berkurung tidak dapat mengurangkan jenayah malah dilihat sebagai mustahil untuk dilaksanakan. ${ }^{6}$ Tambahan pula, Brantley percaya bahawa perintah berkurung dapat menyelamatkan remaja daripada perlakuan jenayah. ${ }^{7}$ Pandangan Brantley disanggah oleh Blumner dengan menyifatkan bahawa perintah berkurung sebagai bercanggah dengan prinsip asas kebebasan diri seseorang remaja. ${ }^{8}$ Beliau menjelaskan seperti yang berikut:

Regardless of the number and breadth of the exceptions, youth curfews violate fundamental civil liberties principles. Those of a certain age are placed under virtual house arrest every night with no charges levied, no right to counsel and no trial. A youth curfew subjects a targeted population to summary punishment based upon an immutable characteristic (age), with no showing of individual criminal culpability.

Sungguhpun begitu, Kline melalui kajiannya membuktikan bahawa perintah berkurung dapat memberi kesan terhadap tingkah laku jenayah dalam kalangan remaja seterusnya dapat mengurangkan jenayah. ${ }^{9}$ Beliau menjelaskan bahawa undang-undang perintah berkurung ini dapat mengurangkan lebih kurang 10 peratus tangkapan terhadap remaja. Oleh yang demikian, undangundang perintah berkurung ini wajar dikaji kesesuaiannya kepada negara-negara lain termasuklah di Malaysia.

\section{UNDANG-UNDANG PERINTAH BERKURUNG DI MALAYSIA}

Perbahasan tentang perintah berkurung ini telah dibangkitkan oleh YB Senator Asmak Husin di dalam perbahasan Kajian Separuh Penggal RMKe-11 di Dewan Negara pada 5 Disember 2018. Dalam ucapan tersebut, Senator berkenaan mencadangkan seperti yang berikut:

“... saya juga ingin mencadangkan agar kerajaan mula merancang untuk menjalankan curfew atau perintah berkurung bagi remaja bawah umur 18 tahun pada waktu malam sebagaimana yang telah diamalkan oleh kebanyakan negara maju seperti US, Iceland, Australia, Jerman, Perancis dan yang paling dekat dengan kita ialah Thailand." 10

Selain perbahasan ini, Senator berkenaan turut bertanyakan soalan menerusi sesi Soal Jawab Lisan dalam Dewan Negara kepada Menteri Pembangunan Wanita, Keluarga dan Masyarakat tentang perancangan kerajaan dalam mengurangkan jenayah dalam kalangan remaja melalui pelaksanaan perintah berkurung. ${ }^{11}$ Namun begitu, pada ketika itu Timbalan Menteri memaklumkan bahawa kerajaan tidak berhasrat untuk melaksanakan perintah berkenaan, sebaliknya ibu bapa dan pemimpin tempatan patut memainkan peranan untuk memastikan kanak-kanak bawah 18 tahun tidak melakukan aktiviti-aktiviti yang tidak sihat pada waktu malam. $^{12}$ 
Namun, perbincangan tentang perintah berkurung kembali diperkatakan apabila Timbalan Perdana Menteri, YAB Dato' Seri Dr Wan Azizah binti Wan Ismail menyatakan bahawa kerajaan bercadang untuk mengadakan perintah berkurung selepas pukul 12 malam bagi remaja yang berumur bawah 18 tahun pada 17 Januari 2019 lalu. ${ }^{13}$ Hal ini adalah untuk mencegah penglibatan remaja dalam aktiviti penyalahgunaan dadah dan penyalahgunaan bahan khayal, seperti ubat-ubat psikotropik (phsychotrophic) dan gam. ${ }^{14}$

Sungguhpun begitu, cadangan ini menerima pelbagai pandangan daripada pelbagai pihak. Menurut wakil UNICEF di Malaysia, Marianne Clark-Hattingh menyifatkan pelaksanaan perintah berkurung ini hanya akan membebankan pihak penguat kuasa, selain bercanggah dengan hak asasi manusia kanak-kanak tersebut. Sebaliknya, beliau mencadangkan langkah restrorative justice dan memperkasakan sistem sokongan melalui pendidikan, kaunseling dan kerja sosial bagi melindungi kanak-kanak berisiko tersebut. ${ }^{15}$ Di samping itu, pakar kaunseling Dr Mahani berpandangan bahawa kerajaan perlu mengkaji secara mendalam tentang pelaksanaan perintah berkurung bagi mengetahui impak pelaksanaanya. Walaupun kanak-kanak ini tidak keluar rumah, mereka akan aktif di alam maya. ${ }^{16}$

Di Malaysia, kerajaan Negeri Perlis di bawah pentadbiran Datuk Seri Shahidan Kassim pada tahun 2003 dahulu telah mencadangkan untuk menguatkuasakan perintah berkurung bagi melarang remaja bawah umur 18 tahun untuk keluar rumah selepas pukul 10 malam sehingga 6 pagi keesokan harinya. Perintah berkurung ini bertujuan untuk melarang atau menyekat remaja daripada mengunjungi tempat hiburan atau tempattempat yang diwartakan sebagai lokasi lumba haram. ${ }^{17}$ Walau bagaimanapun, cadangan ini telah mendapat tentangan oleh pelbagai pihak termasuklah Presiden Majlis Peguam Malaysia ketika itu, Mah Weng Kwai yang menegaskan bahawa remaja yang ditahan kerana melanggar perintah berkurung boleh menyaman semula Kerajaan Perlis di mahkamah. ${ }^{18}$ Bagi pihak masyarakat Perlis pula, rata-ratanya mereka menyambut baik cadangan itu, terutama para ibu bapa yang berasakan bahawa langkah tersebut sepatutnya telah lama dilaksanakan agar dapat mencegah peningkatan gejala negatif dalam kalangan remaja. ${ }^{19}$

Pada tahun 2017, Datuk Nur Jazlan telah menggesa kerajaan Johor untuk mengenakan perintah berkurung bagi mengelakkan pelajar sekolah melepak di sekitar jalan Johor Bahru pada waktu malam. ${ }^{20}$ Gesaan ini dibuat ekoran daripada kemalangan ngeri yang mengorbankan lapan mangsa, manakala dua lagi kritikal dan enam cedera apabila sebuah kereta merempuh sekumpulan 16 remaja berusia antara 8 hingga 16 tahun, yang sedang berbasikal di Jalan Lingkaran Dalam, Johor Bahru. Menurut polis, mangsa merupakan sebahagian daripada sekumpulan 30 hingga 40 remaja yang berumur antara 13 hingga 17 tahun. $^{21}$
Pada masa ini tiada undang-undang khusus yang berkaitan dengan perintah berkurung atau apa-apa undangundang yang melarang remaja bawah umur 18 tahun di negara ini daripada keluar rumah pada waktu malam tanpa ditemani oleh ibu bapa mahupun penjaga. Seksyen 23 Akta Majlis Keselamatan Negara 2016 [Akta 776] memperuntukan tentang perintah berkurung. Sungguhpun begitu, perintah berkurung ini dilihat kabur pemakaianya dalam konteks pencegahan jenayah dalam kalangan remaja bawah umur 18 tahun. Sebelum Akta Mahkamah Juvana 1947 [Akta 90] dimansuhkan, seksyen 12 (1)(b) memperuntukkan klausa yang memerintahkan kanakkanak untuk menghadiri sesi kaunseling, menghabiskan sesi persekolahan, berkurung pada waktu malam dan sebagainya. Namun, akta ini kemudiannya bersama-sama dengan Akta Perlindungan Wanita dan Gadis 1973 [Akta 106] dan Akta Perlindungan Kanak-Kanak 1991 [Akta 468] telah digabungkan untuk membentuk Akta KanakKanak 2001 [Akta 611].

Selain itu, selari dengan konsep hak asasi manusia, pelaksanaan perintah berkurung ini juga perlu mempertimbangkan peruntukan perkara 9(2) Perlembagaan Persekutuan yang menjamin kebebasan bergerak seperti yang berikut:

Tertakluk kepada Fasal (3) dan kepada mana-mana undangundang yang berhubungan dengan keselamatan Persekutuan atau mana-mana bahagiannya, ketenteraman awam, kesihatan awam, atau penghukuman pesalah, tiap-tiap warganegara berhak bergerak dengan bebas di seluruh Persekutuan dan bermastautin di mana-mana bahagiannya.

Peruntukan ini wajar diperhalusi agar apa-apa undang-undang atau dasar yang akan dilaksanakan kepada remaja ini tidak bercanggah dengan Perlembagaan Persekutuan. Tambahan pula, amalan perintah berkurung ini akan menjadi lebih sensitif kerana akan melibatkan remaja bawah 18 tahun.

\section{TINJAUAN AMALAN PERINTAH BERKURUNG DI LUAR NEGARA}

Curfew atau perintah berkurung terhadap remaja berusia kurang daripada 18 tahun telah lama dilaksanakan di negara-negara luar. Antara negara yang ditinjau dalam artikel ini ialah Amerika Syarikat, Iceland dan Kanada.

\section{i. Amerika Syarikat}

Di Amerika Syarikat, pihak berkuasa tempatan telah menguatkuasakan perintah berkurung sejak 1880 di Omaha, Nebraska. Perintah berkurung turut dijadikan sebagai undang-undang kecil di negeri-negeri seperti Georgia, Minnesota, Ohio, Tennessee dan Texas. Namun begitu, pelaksanaan undang-undang ini terikat kepada beberapa pengecualian dan bukanlah bersifat mutlak. Remaja masih dibenarkan untuk keluar pada waktu malam sekiranya ditemani oleh ibu bapa atau penjaga mereka. 
Sekurang-kurangnya 500 buah bandar telah mengenakan perintah berkurung bagi remaja yang berusia bawah umur 18 tahun. Perintah berkurung ini dikenakan selepas pukul 11 malam bagi hari biasa, manakala bagi hujung minggu adalah selepas pukul 12 malam. Mengikut kajian yang dibuat pada tahun 1995, hampir 300 buah bandar telah meluluskan ordinan perintah berkurung, antaranya tadalah Arlington, Austin, Baltimore, Buffalo, Phoenix, Oklahoma City dan San Jose. ${ }^{22}$

Sekiranya seseorang remaja didapati telah berulang kali melanggar perintah berkurung, dia akan dikenakan denda antara AS\$50 hingga AS\$250 atau hukuman khidmat masyarakat atau dipanggil untuk menghadiri kelas pemulihan. Ibu bapa juga berkemungkinan berdepan dengan hukuman pemenjaraan, manakala remaja berkenaan akan ditahan di pusat tahanan juvana sekiranya perlanggaran hukuman perintah berkurung itu dilihat sebagai suatu perlakuan yang serius.

Di St. Louise umpamanya, juvana yang melanggar perintah berkurung akan didenda sehingga AS\$500 atau pemenjaraan sehingga 90 hari. Malahan, ibu bapa juga akan dikenakan hukuman disebabkan oleh kesalahan anak mereka. Menurut rekod oleh Federal Bureau of Investigation, sebanyak 2.6 juta kanak-kanak telah ditangkap atas kesalahan mengingkari perintah berkurung yang ditetapkan sejak tahun 1994 hingga 2012; iaitu lebih kurang 139,000 kanak-kanak setahun. Di Philadelphia sahaja, sebanyak 16,079 kanak-kanak telah ditangkap pada tahun 2014. ${ }^{23}$

Berdasarkan data yang dipamerkan oleh College of Policing, hasil kajian terhadap keberkesanan perintah berkurung di 57 buah bandar telah mendapati bahawa kes-kes berkaitan dengan pecah rumah, curi dan jenayah kecil telah menunujukkan penurunan sebanyak 14 peratus, salah laku jenayah (15 peratus) dan senjata api (29 peratus). ${ }^{24}$

ii. Iceland

Dalam Akta Perlindungan Kanak-kanak Iceland 2002, kanak-kanak yang berumur 12 tahun atau ke bawah tidak boleh berada di luar rumah selepas pukul 8 malam melainkan jika ditemani oleh seorang dewasa. Kanakkanak yang berumur antara 13 hingga 16 tahun tidak dibenarkan berada di luar rumah selepas pukul 10 malam melainkan jika mereka dalam perjalanan pulang daripada program anjuran sekolah, organisasi sukan atau kelab belia. Menurut tinjauan yang dilakukan, peratusan remaja yang mengambil minuman keras dan berumur antara 15 dengan 16 tahun telah berkurangan daripada $42 \%$ pada tahun 1998 kepada 5\% pada tahun 2016. Seterusnya, peratusan remaja yang merokok turut menurun daripada $23 \%$ kepada $3 \%$, manakala penggunaan ganja berkurangan daripada $17 \%$ kepada $7 \%{ }^{25}$

iii. Kanada

Perintah berkurung telah diperuntukkan dalam The Child and Family Services Act 2017, melalui seksyen 136 (4) yang menyatakan bahawa:
1. loiter in a public place between the hours of midnight and 6 a.m.; or

2. be in a place of public entertainment between the hours of midnight and 6 a.m., unless the parent accompanies the child or authorizes a specified individual eighteen years of age or older to accompany the child.

Kanak-kanak yang melanggar perintah berkurung di negara ini akan dikenakan tindakan mengikut seksyen 136(5) yang menyebut:

Where a child who is actually or apparently less than sixteen years of age is in a place to which the public has access between the hours of midnight and 6 a.m. and is not accompanied by a person described in clause (4) (b), a peace officer may bring the child to a place of safety without a warrant and proceed as if the child had been brought to a place of safety under subsection 84 (1).

Peruntukan ini menunjukkan bahawa kerajaan mengambil serius dalam mengawal tingkah laku remaja dengan mewujudkan undang-undang yang jelas bagi mengekang jenayah dalam kalangan remaja.

\section{KESIMPULAN}

Persoalan sama ada perintah berkurung mampu membanteras jenayah dalam kalangan remaja hanya dapat dijawab sekiranya pihak kerajaan membuat pertimbangan yang sewajarnya serta melaksanakan kajian yang lebih rinci tentang impak dan kesesuaian undang-undang berkaitan dengan perintah berkurung kepada remaja bawah 18 tahun. Malaysia boleh mencontohi modelmodel pelaksanaan perintah berkurung kepada remaja yang diamalkan di luar negara dengan beberapa modifikasi agar bersesuaian dengan nilai dan norma tempatan. Hal ini juga bagi mengelakkan undang-undang yang dibentuk kelak adalah tidak holistik yang menyebabkan aspek pelaksanaannya menjadi tidak efektif. Sebagai sebuah negara anggota kepada Konvensyen tentang Hak KanakKanak 1995, Malaysia perlu menghayati falsafah dan prinsip yang mendasari sistem perundangan juvana di negara ini agar dapat melindungi kanak-kanak daripada menjadi mangsa atau terjebak dengan kegiatan jenayah. Oleh hal yang demikian, usaha untuk membanteras jenayah khususnya penyalahgunaan dadah dalam kalangan remaja perlu diteliti sedalamnya agar undangundang pelaksanaan perintah berkurung tersebut adalah berkesan tanpa melanggar peruntukan perlembagaan persekutuan dan prinsip hak asasi manusia.

\section{PENGHARGAAN}

Sebahagian daripada maklumat dalam artikel ini ialah kajian yang dibiayai oleh Geran Kementerian Pendidikan Malaysia, iaitu Dana Pembudayaan Penyelidikan (RAGS) Kod 2015-0181-107-72 (RAGS/1/2015/SS10/UPSI02/4). 
NOTA

Azizan, H., Adakah Belia semakin Ganas? Mstar Online: http:// www.mstar.com.my/berit a/berita-semasa/2017/09/24/juvana/, tarikh 24 September 2017 diakses pada 20 Jun 2019.

2 Hak Untuk Semua Kanak-kanak, Panduan Media, The Conventions on the Rights of the Child, UNICEF diakses melalui: https://www. unicef.org/malaysia/media-guide-child-rights-malay.pdf, diakses pada 26 Jun 2019.

3 Buang, D. S., Perlukan juvana dikena 'perintah berkurung'? (2017, 27 Februari) diakses melalui https://www.bharian.com.my/node/25 3507, diakses pada 26 Jun 2019.

4 Buang, D. S., Perlukan juvana dikena 'perintah berkurung'? diakses melalui https://www.bharian.com.my/node/253507.

5 Townsend, J.D, Curfew for City Children, (1896) 163 (481) The North American Review, hlm 725.

6 Buck, Winifred, Objections to a Children's Curfew, (1897) 164(484) The North American Review, hlm 381.

7 Overtis Hicks Brantley \& Robyn E. Blumner, Curfews For Juveniles: More And More Cities Are Adopting Them, But Are They Constitutional? (1994) 80 (4) Aba Journal, hlm 40.

8 Overtis Hicks Brantley \& Robyn E. Blumner, Curfews For Juveniles: More And More Cities Are Adopting Them, But Are They Constitutional?, hlm 41.

9 Kline, Patrick, The Impact of Juvenile Curfew Laws on Arrests of Youth and Adults, (2012) 14 (1) American Law and Economics Review, 44-67, hlm 44.

10 Penyata Rasmi Dewan Negara, Parlimen Keempat Belas, Penggal Pertama, Mesyuarat Kedua, 5 Disember 2018, ms 84.

11 Aturan Urusan Mesyuarat Dewan Negara, Pertanyaan-Pertanyaan Bagi Jawab Lisan, Hari Rabu, 12 Disember 2018, Pukul 10.00 Pagi.

12 Penyata Rasmi, Dewan Negara, Parlimen Keempat Belas, Penggal Pertama, Mesyuarat Kedua, 12 Disember 2018, hlm 26.

13 Astro Awani, http://www.astroawani.com/berita-malaysia/ruubahan-khayal-digubal-tangani-ketagihan-gam-dr-wan-azizah196391 (17 Januari 2019) diakses pada 27 Julai 2019.

$14 \mathrm{https}: / /$ mnews.host/kerajaan-kaji-perintah-berkurung-selepas-jam12malam-kepada-remaja-dibawah-18-tahun/ (17 Januari 2019) diakses pada 27 Julai 2019.

15 http://www.astroawani.com/berita-malaysia/perintah-berkurunguntuk-remaja-tidak-beri-kesan-efektif-unicef-malaysia-196425, (19 Januari 2019) diakses pada 27 Julai 2019

16 http://www.astroawani.com/berita-malaysia/apa-guna-perintahberkurung-sekiranya-remaja-berkeliaran-di-alam-maya-pakar196422 (19 Januari 2019) diakses pada 27 Julai 2019.

17 Shahidan jelas definisi 'perintah berkurung,' Utusan Online, (14 Januari, 2003) http://ww1.utusan.com.my/utusan/info. asp $? \mathrm{y}=2003 \& \mathrm{dt}=0114 \& \mathrm{pub}=$ Utusan_Malaysia $\&$ sec $=$ Dalam Negeri\&pg=dn_09.htm, diakses pada $2 \overline{7}$ Julai 2019.

18 Shahidan jelas definisi 'perintah berkurung,' Utusan Online, (14 Januari, 2003) http://ww1.utusan.com.my/utusan/info. asp $? \mathrm{y}=2003 \& \mathrm{dt}=0114 \& \mathrm{pub}=$ Utusan_Malaysia $\&$ sec $=$ Dalam Negeri\&pg=dn_09.htm, diakses pada 27 Julai 2019.

19 Bakar, S. A.). Perintah berkurung remaja disokong. Retrieved from Utusan Online (11 Januari, 2003: http://ww1.utusan.com.my/u tusan/ info.asp? $=2003 \& \mathrm{dt}=0111 \&$ pub $=$ Utusan_Malaysia \&sec=Dalam Negeri\&pg=dn_0, diakses pada 27 Julai 2019.

20 Augustin, R., Tragedi basikal: Sedih tapi tak tragik, kata Nur Jazlan. Diakses melalui Free Malaysia Today (2017, 18 Februari) https:// www.freemalaysiatoday.com/category/bahasa/2017/02/18/tragedibasikal-sedih-tapi-tak-tragik-kata-nur-jazlan/, diakses pada 27 Julai 2019.

21 Augustin, R., Tragedi basikal: Sedih tapi tak tragik, kata Nur Jazlan. Diakses melalui Free Malaysia Today (2017, 18 Februari) https:// www.freemalaysiatoday.com/category/bahasa/2017/02/18/tragedibasikal-sedih-tapi-tak-tragik-kata-nur-jazlan/, diakses pada 27 Julai 2019.
22 Buang, D. S., Perlukan juvana dikena 'perintah berkurung'? (2017, 27 Februari) diakses melalui https://www.bharian.com.my/ node/253507, diakses pada 27 Julai 2019.

23 Life under curfew for American teens: 'it's insane, no other country does this,' The Guardian, https://www.theguardian.com/ us-news/2016/may/28/curfew-laws-san-diego, diakses pada 27 Julai 2019.

24 Youth Curfews, College of Policing, http://whatworks.college. police.uk/toolkit/Pages/Intervention.aspx?InterventionID=21, diakses pada 27 Julai 2019.

25 Abu Bakar, S. K., NGO: Perintah berkurung untuk remaja cadangan baik, tetapi...(2017, 8 Disember)

\section{RUJUKAN}

Adakah Belia Semakin Ganas? 2017. http://www.mstar.com. my/berita/berita-semasa/2017/09/24/juvana/

Astro Awani. 2019. RUU bahan khayal digubal tangani ketagihan gam, http://www.astroawani.com/beritamalaysia/ruu-bahan-khayal-digubal-tangani-ketagihangam-dr-wan-azizah-196391.

Astro Awani. 2019. Perintah berkurung untuk remaja, tidak beri kesan efektif - UNICEF Malaysia, http:/www.astroawani. com/berita-malaysia/perintah-berkurung-untuk-remajatidak-beri-kesan-efektif-unicef-malaysia-196425.

Astro Awani. 2019. Apa guna perintah berkurung sekiranya remaja berkeliaran di alam maya? http://www.astroawani. com/berita-malaysia/apa-guna-perintah-berkurungsekiranya-remaja-berkeliaran-di-alam-maya-pakar196422.

Aturan Urusan Mesyuarat Dewan Negara, PertanyaanPertanyaan Bagi Jawab Lisan, Hari Rabu, 12 Disember 2018, Pukul 10.00 Pagi.

Bakar, S. A. 2003. Perintah berkurung remaja disokong. Diakses melalui Utusan Online: http://ww1.utusan.com. my/utusan/info.asp? $=2003 \& \mathrm{dt}=0111 \&$ pub=Utusan Malaysia\&sec $=$ Dalam_Negeri\&pg $=\mathrm{dn} \_03 . \mathrm{htm}$.

Buck, W. 1897, Objections to a Children's Curfew, The North American Review, 164 (484) hlm 381-384.

Buang, D. S. 2017. Perlukah juvana dikena 'perintah berkurung'? Diakses melalui Berita Harian Online: https:// www.bharian.com.my/node/253507.

Kline, P. 2012. The Impact of Juvenile Curfew Laws on Arrests of Youth and Adults, American Law and Economics Review, V14 N1. hlm 44-67.

Mnews. 2019. Kerajaan Kaji Perintah Berkurung selepas jam 12 malam kepada Remaja di bawah 18 tahun, (17 Januari 2019) https://mnews.host/kerajaan-kajiperintah-berkurung-selepas-jam-12malam-kepada-remajadibawah-18-tahun/.

Overtis Hicks Brantley And Robyn E. Blumner, Curfews For Juveniles: More And More Cities Are Adopting Them, But Are They Constitutional? Aba Journal, Vol. 80, No. 4 (April 1994), Pp. 40-41.

Penyata Rasmi Dewan Negara, Parlimen Keempat Belas, Penggal Pertama, Mesyuarat Kedua, 5 Disember 2018.

Penyata Rasmi, Dewan Negara, Parlimen Keempat Belas, Penggal Pertama, Mesyuarat Kedua, 12 Disember 2018.

Shahidan jelas definisi 'perintah berkurung.' 2003. http://ww1.utusan.com.my/utusan/ info.asp? y $=2003 \& d t=0114 \&$ pub=Utusan Malaysia\&sec $=$ Dalam_Negeri\&pg $=$ dn_09.htm 
Siti Balqis Mohd azam, S. H. (n.d.). Terapi pelbagai sistem untuk pemulihan kanak-kanak yang disabitkan Dengan kesalahan jenayah: konsep, andaian, prinsip dan intervensi. The Malaysian Journal of Social Administration: 24-41.

Townsend, J. D. 1896. Curfew for city children. The North American Review 163(481): 725-730.

UNICEF. 2009. Hak Untuk Semua Kanak-kanak: Panduan Media. Kuala Lumpur: UNICEF.

Youth Around the World. 2017. https://www.thestar.com. $\mathrm{my} /$ news/nation/2017/02/26/youth-curfew-around-theworld/\#ZCFKiAZyTF61cZpq.99.

Muhamad Sayuti bin Hassan@ Yahya,

Pensyarah Kanan

Fakulti Sains Kemanusiaan

Universiti Pendidikan Sultan Idris

Tanjong Malim, Perak Darul Ridzuan

Email: sayuti@fsk.upsi.edu.my

Rozana Abdullah

Pegawai Penyelidik

Parlimen Malaysia, Kuala Lumpur

Email: rozana@parlimen.gov.my 